\title{
HearMe: a Touch-to-Speech UI for Medicine Identification
}

\author{
Marja Harjumaa $^{\# 1}$, Minna Isomursu ${ }^{\# 2}$, Salla Muuraiskangas ${ }^{\# 3}$, Antti Konttila ${ }^{\# 4}$

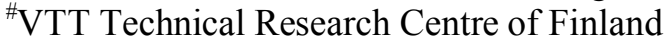 \\ Oulu, Finland \\ ${ }^{1}$ marja.harjumaa@vtt.fi \\ ${ }^{2}$ minna.isomursu@vtt.fi \\ ${ }^{3}$ salla.muuraiskangas@vtt.fi \\ antti.konttila@vtt.fi
}

\begin{abstract}
${ }^{1}$ Abstract - This article describes a medication management service concept for visually challenged older users. The service transforms medication information into speech. This can help visually challenged individuals to identify medication, and to find dosage and other consumption-related information. The user interface is based on Near Field Communication (NFC) technology, which makes it possible to write and read data in tags, which can be attached to medication packages. A speech synthesizer transforms the text stored in the tag into audio message. A complete service covering the service chain from pharmacy to user's home was implemented and evaluated. Findings from a field trial are presented, exploring how the service was adopted in the medication management. The results show that, while the users found the service easy to learn and use, they found the service concept difficult to integrate with their existing medication management practices.
\end{abstract}

Keywords; Field trial, older users, medication management, NFC, RFID, audio interface, touch-based user interface, touch-tospeech user interface, universal access, qualitative research

\section{INTRODUCTION}

As a result of general improvement in life-expectancy and low birth and mortality rates, the number of older people in developed societies is growing. As an example, in 2010, 17.4\% of the population in EU countries are over 65 years old, and the number is expected to grow to $23.6 \%$ in twenty years [1]. Even though people generally are healthier, aging does have its effects on our physiology. One of the inevitable changes is a deterioration in our eyesight. Age-related illnesses as well as a natural deterioration in our senses threaten the independent lives of the elderly in their own homes. However, people usually prefer living in their homes as long as possible, and this is also most beneficial for society, too. It has been discovered that older people use from four to six medications on a daily basis [6], [7]. Research shows that older people have difficulties in managing their medication. Beckman et al. [4] have found in their studies that $9.4 \%$ of elderly Swedish people

The research presented in this paper has been funded by VTT Technical Research Centre of Finland, the Finnish Funding Agency for Technology and Innovation (TEKES) and Ambient Assisted Living (AAL) Joint Programme (project HearMeFeelMe). cannot read the instructions on the label of a medicine bottle, and that $66.2 \%$ of are not able to accomplish all of the tasks related to their medication management, including the ability to read medication labels, open a medication container, ability to understand instructions, etc. They also found that vision, memory and comprehension, hand function and mobility are crucial for the process of medication management. Thus, medication management is one factor adding to care needs in the home environment.

Medication compliance could be improved by giving the responsibility for management to someone else, either to a healthcare professional or a close relative or friend. However, research indicates that people find it important to take responsibility for their medication personally. In addition, the services may be too expensive and trustworthy people do not always live close by. There is also a wide selection of innovative medicine dispensers on the market, but their usefulness is limited to supporting the memory rather than the vision. The medicine management of visually impaired people has been supported, for example, by including the name of the medicine in Braille letters on medicine packages. However, many who have vision impairments due to aging cannot read Braille text, as it is cognitively challenging and requires good sensing ability in the fingertips - both skills that are also affected by aging.

In an ambient environment, the physical world is augmented with digital information, such as digital services and other information available to the user, and it is seamlessly integrated into the physical world [2]. Near Field Communication (NFC) is a promising technology for bridging the physical and virtual worlds, because it is a communication technology for transferring digital information wirelessly over a short range between objects. NFC technology is based on Radio Frequency Identification (RFID), which has been widely used in production, transportation, and sales of merchandise. It has also been used in the pharmaceutical industry as well as in hospitals for automatic identification of drugs in storage and improving drug safety [19], [15]. With an NFC-enabled device, such as a PDA or a mobile phone, a user is able to identify objects, receive information, and select services by touching an NFC tag. Conventional UI's, with displays and keypads, are not necessarily needed, which provides opportunities for user interface implementations especially suited for the visually 
impaired. It has been discovered that touch-based interaction is an easy and intuitive way to access information [18]. NFC technology has also been applied in ordering meal services by older users [9].

This study particularly concentrates on the problem of identifying a medication package and internalising the medication instructions. People with visual impairments have difficulties in reading the textual information on medication packaging. Therefore, they might face problems in finding the correct medication package and reading the related instructions for dosage, the recommended time for taking the medication etc. In the HearMe trial, we explored the issues related to adoption and use of the medication management service with a touch-to-speech user interface in the homes of the eight older people. The research questions of this study are as follows:

How well are the users able to adopt and use the service?

How useful do the users find the service concept, and what are the possible barriers to technology adoption in the context of technology pilot?

The field trial also involved the pharmacy and the company providing care services for trial users. However, in this paper we concentrate solely on analyzing use and adoption from the viewpoint of ageing users.

\section{RESEARCH SETTING}

\section{A. Defining the service concept}

The need for the service concept emerged from a co-design process involving technology providers, care personnel and personnel of the federation of the visually impaired, pharmacy professionals, and older visually impaired users. A set of requirements for the service concept were identified:

The new service concept should:

- be channelled to cover all medication sold - both overthe-counter and prescription medication

- ensure quality and validity of the information

- not dramatically change the medication delivery process

- cover both daily medications and medications taken occasionally, e.g. in the case of the asthma attack

- cover medication in different formats, e.g. liquid, powder, and pills

- cover medication stored in different places, e.g. a kitchen cabinet or fridge

- not dramatically change the consumption process for the medication

- not incur unacceptable costs for the medication supplier or the end-user

- contain components that will be commercially available within a couple of years.
The result of the co-design process is a service concept based on the idea that the medication-related information (medication name, dosage instructions etc.) are stored into a NFC tag at the pharmacy. The tag is created and attached to the medication package by a pharmacy professional upon request. At home, the user will touch the tag with an NFC-enabled device, and medication information stored in the tag is converted into speech. The co-design process and the service scenarios are described in detail in [10].

\section{B. Development of HearMe}

In order to demonstrate the feasibility of the service concept, an experimental setup called HearMe was developed. It is a contactless service utilizing a touching paradigm. Contactless as a term refers usually to a radio frequency-based technology used, for example, in smart cards, and it means that information is exchanged between devices or objects by simply setting them side by side. Touching is one of the three paradigms of physical browsing which can be used in ambient environments. It means that the tag (object) of interest is chosen by virtually touching it with a reader (mobile device) [2]. In addition, the service uses text-to-speech for transforming the text stored in the tag into speech. Thus, the user interface here is called touch-to-speech UI.

The setup was developed using commercially available components; namely a laptop computer, loudspeakers, and an external NFC reader (see Fig. 1). A mobile phone with NFC would have been preferred to the laptop computer, but at the time of the trial, no suitable mobile phones were available on the market. The benefit of the mobile device would be that (1) most older users already have a mobile phone, so the service could be integrated to familiar and existing technology which could ease its adoption, and (2) a mobile solution would allow more variation in context, e.g. allow the storage of medication in different places and be available when away from home. The shortcomings of a fixed laptop setup were acknowledged.

A complete service covering the whole service chain from pharmacy to the user's home was implemented. One pharmacy was equipped with the required hardware and software, and all medicine packages of the users were tagged at this pharmacy.

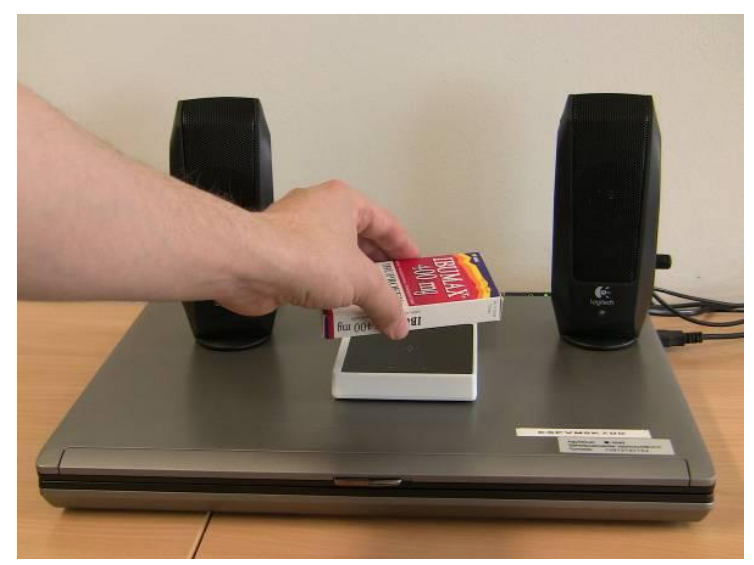

Figure 1. System setup with a laptop, external USB NFC reader and loudspeakers. 


\section{1) Hardware}

The hardware setup consisted of a laptop, and an FEIG CPR40.30-USB NFC reader/writer. The end user setup also included loudspeakers. The type of tag was HF MiniTrack NFC Wet Mifare Std 1k 18mmx36mm.

\section{2) Pharmacy application}

The pharmacy application is used to write the personalized medicine information to the tag. The pharmacist attaches the tag to the medicine package and places the package on top of the NFC reader/writer. Then she or he writes the medicine information from the prescription, namely name of the medicine, customer's name, purchase date, and dosage instructions. The user interface is quite simple, containing only a form with text boxes and a button for saving. In the field trial, the full service chain was implemented, i.e. the tags were attached to the medication packages by pharmacists in a pharmacy.

The standard procedure at the pharmacy in Finland includes printing a prescription label including dosage and other instructions written by the doctor. The pharmacist writes this information with a computer, and prints the label. The same information is now written to the NFC tag with the new pharmacy application.

\section{3) End-user application}

An application installed on a user's laptop is used to read the information from the tag and to transform it into audio. The user places the tagged medication package on the NFC reader, and the speech synthesizer reads the information aloud. The application uses Loquendo's speech synthesizer with a Finnish male voice called "Mikko". A male voice was chosen because it has been found that it is preferred to a female voice in the age group over 65 years [12]. The male voice has also been found to be friendlier and more credible than a female voice [17].

\section{Participant profile}

Participants in the field trial were visually impaired older people who needed regular medications. They were selected using 'purposeful sampling' [14]. Units of analysis are individual people who are perceived to be especially information-rich cases. The selection of participants was nonrandom, and specific inclusion criteria were used in the selection. It was required that the participant a) is able to manage the medication independently without support from formal care, b) is visually impaired or has some problems with their eyesight, c) is an older person (over 65 years) and retired, d) does not suffer from severe memory problems, e) does not suffer from severe motor problems, and f) does not suffer from severe hearing problems.

The first four of our users were recruited from a sheltered home with the help of the personnel. They were living alone or with their spouses in apartments located on, the premises of the service provider. The other four users were recruited with the help of a federation of the visually impaired and thus they were living in their own apartments alone or in the case of one user together with his spouse.

The ages of the users varied from 69 to 89 . Five of them had severely impaired vision as a consequence of a heart attack, cataract, dystrophy, or poor vision since birth, and three of them were able to see with spectacles. Table 1 summarizes user profiles.

At the start of the trial, the established medication management practices of the participants were studied in detail. All of them had several medications (ranging from three to nine) that they needed to take regularly. At the beginning of the trial, the medications were taken to the pharmacy where they were tagged. They included both prescribed and over-thecounter medications, and both long-term and periodic medications. An informed consent was required from the participants for handling the medication and the medication information during the project.

It was challenging to find users who have several medications, who are not using a medicine dispenser, and who would be interested in taking part this study. As a consequence, participants who are using medicine dispensers were also allowed to participate. Five users (U=user, U1, U2, U6, U7, U8) had medicine dispensers which they filled once a week or every two weeks; one user had a medicine dispenser which was filled by his spouse (U5), and one user had a one-day medicine dispenser which she filled herself(U4).

TABLE I. USER PROFILES.

\begin{tabular}{|c|c|c|c|c|c|}
\hline User & Age & Gender/ & Eyesight & \multicolumn{2}{|c|}{ ICT experience } \\
\hline 1 & 87 & $\begin{array}{l}\text { Male living } \\
\text { with a spouse }\end{array}$ & Presbyopia & $\begin{array}{l}\text { Uses } \\
\text { phone }\end{array}$ & mobile \\
\hline 2 & 74 & $\begin{array}{l}\text { Male living } \\
\text { alone }\end{array}$ & Presbyobia & $\begin{array}{l}\text { Uses } \\
\text { phone } \\
\text { computer }\end{array}$ & $\begin{array}{r}\text { mobile } \\
\text { and }\end{array}$ \\
\hline 3 & 84 & $\begin{array}{l}\text { Female living } \\
\text { with a spouse }\end{array}$ & $\begin{array}{l}\text { Severe visual } \\
\text { impairment } \\
\text { caused by } \\
\text { heart attack }\end{array}$ & $\begin{array}{l}\text { Uses } \\
\text { phone }\end{array}$ & mobile \\
\hline 4 & 73 & Female & $\begin{array}{l}\text { Presbyopia, } \\
\text { cataract }\end{array}$ & $\begin{array}{l}\text { Uses } \\
\text { phone } \\
\text { computer }\end{array}$ & $\begin{array}{r}\text { mobile } \\
\text { and }\end{array}$ \\
\hline 5 & 69 & $\begin{array}{l}\text { Male living } \\
\text { with a spouse }\end{array}$ & $\begin{array}{l}\text { Severe visual } \\
\text { impairment, } \\
\text { dystrophy }\end{array}$ & $\begin{array}{l}\text { Uses } \\
\text { phone }\end{array}$ & mobile \\
\hline 6 & 69 & $\begin{array}{l}\text { Male living } \\
\text { alone }\end{array}$ & $\begin{array}{l}\text { Severe visual } \\
\text { impairment } \\
\text { since birth }\end{array}$ & $\begin{array}{l}\text { Uses } \\
\text { phone } \\
\text { computer }\end{array}$ & $\begin{array}{r}\text { mobile } \\
\text { and }\end{array}$ \\
\hline 7 & 89 & $\begin{array}{l}\text { Female living } \\
\text { alone }\end{array}$ & $\begin{array}{l}\text { Severe visual } \\
\text { impairment, } \\
\text { dystrophy }\end{array}$ & $\begin{array}{l}\text { Uses } \\
\text { phone }\end{array}$ & mobile \\
\hline 8 & 79 & $\begin{array}{l}\text { Female living } \\
\text { alone }\end{array}$ & $\begin{array}{l}\text { Severe visual } \\
\text { impairment } \\
\text { since birth }\end{array}$ & $\begin{array}{l}\text { Uses } \\
\text { phone } \\
\text { computer }\end{array}$ & $\begin{array}{r}\text { mobile } \\
\text { and }\end{array}$ \\
\hline
\end{tabular}

\section{Evaluation procedure}

The HearMe experimental setup was evaluated in a qualitative field trial. The field trial was chosen as a method, because it is suitable for acquiring an understanding of how people use the service or application in real-life situations, and its practical impacts in the lives of its users. Based on the trial findings, it is possible to articulate recommendations for 
improvements and assess the market value [5]. In this case, we were especially interested in acquiring information related to ease of use and the adoption of touch-to-speech user interface.

The trial users used the service in their own homes for four to six weeks. The field trials were carried out in two successive trial phases, with four users in both phases, and the system was updated after the first phase based on the findings.

In order to avoid misunderstandings, the users were given a clear explanation of the purpose of the service. They were also informed about the length and goal of the study in general terms.

At the beginning of the field trial, the users were interviewed and familiarised with the system. The first use situation was observed by two researchers, and field notes were written to capture the researchers' observations. All interviews were recorded. During the trial period, a $\log$ of the actual system use was stored. Interview questions concerned user's background information, eyesight, medication, ICT experience, need for support in medicine management, expectations, and initial use experience observed when learning to use the service.

At the end of the field trial, a final interview was conducted. Interview questions in the final interview concerned perceived usefulness, usability, appropriateness of the information provided, use experience, problems, perception of security, trust, and final use experience. The field notes, transcripts and log data were analyzed with content-based methods.

\section{RESULTS}

The main findings of the study are described in this section and are grouped into findings related to III.A) ease of adoption and use, III.B) perceived usefulness and IIII.C) barriers to use. The user comments used to illustrate findings are translated by the researchers.

\section{A. Ease of adoption and use}

Our findings show that all users found the service concept easy to comprehend. All were able to easily learn and use the service for identifying their medication and internalize their personal medication information. Regardless of their prior computer skills, the users stated that the touch-to-speech user interface is easy or very easy to use. Their technical skill level or background did not seem to have a bearing on their abilities to use the service. Here are users' comments when they were asked about ease of use (translated into English by the authors):

Yes, it was easy (male, 87)

Yes, it is easy to use. And if you can't see these (dosage information on the medication package) you can check. (female, 73)

Yes, I have used it (service) and it wasn't difficult. (female, 79)

Based on the log information, five users' usage patterns are in line with their medication management processes (U1-U4, U8), whereas three users have more or less just tried out the service during the trial (U5-U7). Table 2 summarizes the service usage information. All users who lived in apartments located on the premises of the care service provider were committed to use the service during the field trial, and their use sequence remained about the same from the beginning of the trial to the end.

TABLE II. SERVICE USAGE DURING THE STUDY (THE USAGE SESSIONS DURING THE INITIAL AND THE FINAL INTERVIEW ARE NOT COUNTED IN THE FIGURES).

\begin{tabular}{|l|l|l|l|}
\hline User & Trial days & Usage sessions & \multicolumn{1}{c|}{ Usage pattern } \\
\hline 1 & 46 & 92 & twice a day \\
\hline 2 & 47 & 8 & once a week \\
\hline 3 & 30 & 38 & $\sim$ once a day \\
\hline 4 & 60 & 63 & $\sim$ once a day \\
\hline 5 & 35 & 2 & trying out twice \\
\hline 6 & 33 & 12 & $\begin{array}{l}\text { trying out every now } \\
\text { and then }\end{array}$ \\
\hline 7 & 26 & 4 & trying out 4 times \\
\hline 8 & 26 & 3 & $\sim$ once a week \\
\hline
\end{tabular}

The experimental setup proved to be very reliable, and users did not need any technical support during the study. However, some usability problems were identified regarding the use of contextual cues, the order of the information provided to the user, the clarity and speed of the speech synthesizer and NFC tags. The problems and the respective solutions are described in detail as follows.

At the beginning of the trials, contextual cues were not used to describe the information content. For example, for information about purchase date, only the date was read aloud. This was found to be problematic as the users did not understand the meaning of the date. This was corrected by adding contextual cues to make the contents more informative. Cues such as "medicine expires", "name of the medication is" and "dosage instructions are" were used.

At first, the medication information was read in the same order as it was written on the tag (the order described in chapter 2). The medication name was read first, which was problematic for some users. They commented that it came too "suddenly" and that they missed the information. Thus, the application was modified so that is was possible to personalize the order of information for each user. Often, the user's name was the first information item to be read aloud to catch the user's attention before more important information items.

The speech of the synthesizer was considered to be too fast by two users and too slow by one user. The foreign words, such as medicine names, were sometimes pronounced unclearly and one participant in particular had difficulties in understanding them (U3). One user also requested longer pauses between information. Based on user comments, the HearMe application was updated in order to add additional pauses to speech and to personalize the speech synthesizer according to user's preferences by adjusting the speed and pitch of the synthesized speech.

There were also some usability problems related to tags. The reading distance of the NFC tags is short, and thus, the user has first to find the tag attached to the medication package 
in order to position the medication package correctly on top of the NFC reader device. During the first phase, it was problematic for some users to find the tags, because they had an impaired sense of touch (U2), they had difficulties in distinguishing them by eye from the rest of the medicine package (U2, U4), and the tags were attached in varying locations in the medication package by the pharmacist. The tags were light silver-coloured and partially transparent and they had a smooth surface structure.

Sometimes the NFC reader did not read the tag. The shape of the medicine packages varied, and some problems occurred while reading a tag that was attached to a curved surface e.g. to a pill bottle or tube (see Fig. 2). The reason was that curvature of the tag caused a geometry change in the antenna of the NFC tag and resulted in a reading failure. Also, foil pill packs (inside a cardboard package) sometimes caused reading failure because they blocked radio waves.

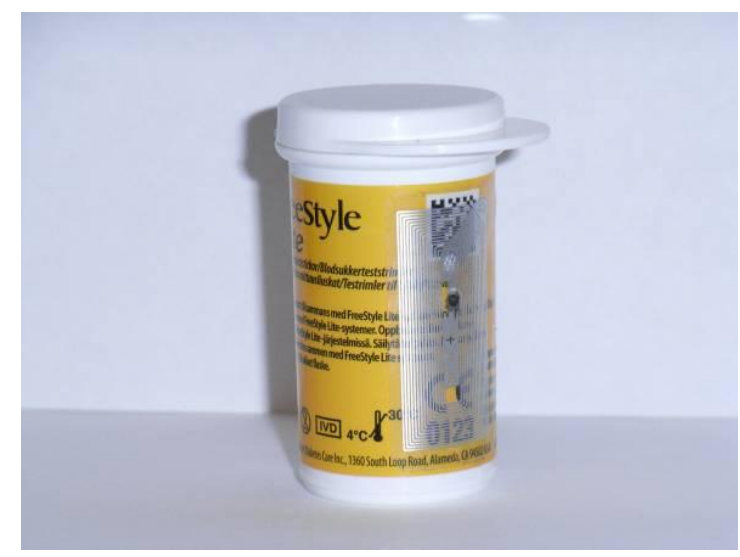

Figure 2. Tags attached to a curved surface were not always read properly.

It was noticed that it is better if the tags are attached to the back of the prescription label attached to the medicine package by only one edge, leaving the rest of the label free (see Fig. 3). These labels are a de facto standard in Finland, and they are always attached to prescription medicine packages.

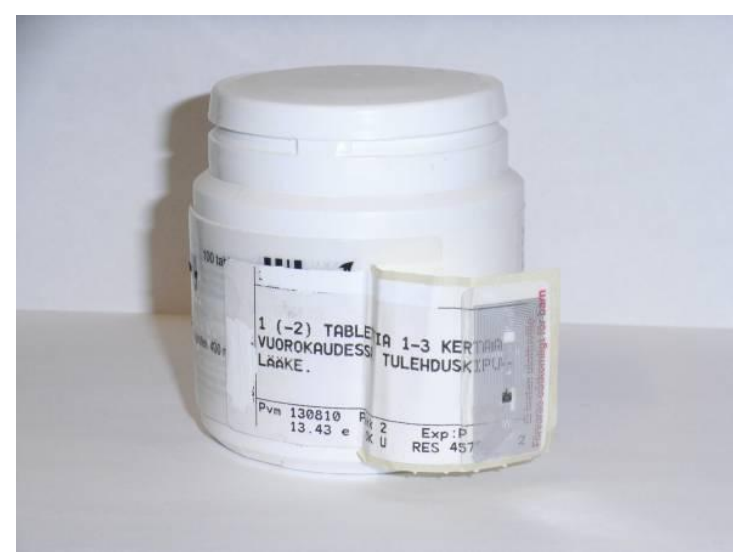

Figure 3. Tags attached to a prescription label were more usable.

\section{B. Perceived usefulness}

All trial users stated that the service could be useful and could help someone. They were not, however, willing to adopt it in their everyday life, even when everybody found it easy to use. A typical reaction was that the system is not really useful, but it is "no harm either".

Researcher: You believe that someone would benefit from using this system?

Yes, I'm sure. I'm sure that someone would benefit from this. Yes. (female, 84)

Three users stated they would probably be interested in using the service in the future. Two users said that they might be interested in it, if it could be used with a mobile phone with NFC instead of a laptop, and if it included a medicine reminder functionality (U2) and a control for preventing overdose (U4). One user, who was living alone and whose eyesight was deteriorating, said that the service might be useful for her in the future (U8), as described in the following comment:

Well, because I'm near-sighted, I'm still able to see... For that reason, it is not useful for me at the moment. But I know that the situation is getting worse and it might be very useful some day. (female, 79)

A couple of users doubted the service concept in general. They doubted the capability of blind people to manage their medications and fill their medicine dispensers by themselves. They also supposed that almost all elderly people (except themselves) have medicine dispensers and have help available, e.g. nurses. This is illustrated in the following comments:

Actually, probably everybody has a medicine dispenser and when it is being filled there is another person in the room who can do it. (male, 74)

It doesn't happen, for sure (that a visually impaired person would be able to fill a medicine dispenser). (female, 84)

All users found the medicine information trustworthy, and they did not see any information security threats to using the service at home. Thus, the credibility of the medicine information or information security issues were not perceived as barriers to adopting the service.

In general, the touch-to-speech interface was favourably received. The participants' attitudes toward the service concept were mostly positive in general, and the speech of the synthesizer was found to be pleasant. The service was even of some entertainment value for users, and they had showed it to their guests as described in the following comment:

Researcher: Is the voice pleasant?

Yes and it is clear. (female, 73)

Researcher: Did you test (more like try for fun) the device in the beginning?

Yes, you bet. And when some visitors came, of course I had to let them listen for a while. (female, 73)

It was discovered that the users did not consider themselves as the potential users of the service, because they thought that 
they still had eyesight left that provided sufficient help. Even if the participants had severe visual impairments, most of them were still able to read when they looked really closely, or with the help of reading aids. They stated that the service is not something they personally need at the moment. Users thought that the potential user group for the service would be people with more severe visual impairments (or blind people) who are living alone.

This would be really nice for those who can't see. (female, 79)

It should be mentioned, however, that sometimes users seemed to perceive their abilities to be better than they actually were. They consider that they are able to see well enough, if they are able to see something. As an example, one participant whose lenses were at a power of -15.5 said that she is still able to see well enough (U8). According to definition [16] she had visual impairment (visual acuity 0.05 in the left and 0.3 in the right eye).

During the initial interview it was found that the participants did not feel they had many problems with their medication management. Only one user (U4) reported problems in distinguishing two similar medicine packages, but all the others trusted that they are able to recognise the medicine packages correctly and remember the dosages. One participant reported problems in remembering to take the medicine (U2) and one in opening the medicine packages (U3). One participant was not able to manage his medication by himself due to the loss of his eyesight, and his wife had taken care of the medication management (U5). Most of the users did not feel that the service would improve their medication safety, and only one user found that the service would give her some sense of security (U4). Thus, the participants found that they do not have a need for the service and that it does not improve their feelings of safety either, as illustrated in the following comments.

No it didn't (change my medication consumption) because I take medicines very regularly. This matter didn't make any difference. But no harm either. (male, 87)

One factor explaining not having problems with medication management was that most of the users' medication plans had been the same for many years, and they were able to remember their personal dosages. Participants considered that the service might be useful if the medication plan were to change, as described in the following:

\section{Researcher: Was the system easy to use?}

Yes, it is not up to it (why I don't find it useful). This is simply easy to use. When new medicines appear, and if you don't quite remember what it was now, so then it helps. (female, 84)

The established medication management practises of the users were studied. It was discovered that the users were reluctant to change their behaviour, because the service did not provide enough added value for them compared to their own methods which they had developed over a long time.

Five participants were still able to identify them with their eyesight (U1, U2, U4, U6, U8) if they also used other methods in addition. One of them evaluated the shape and feel of the individual pills and she also used a magnifying glass when necessary (U4). Two of the users who still used their eyesight had medicine packages that were quite similar (U4, U8). Other of them worried that she might not be able to recognise them in the future, but at the moment she was still able to recognise the packages if she looked really closely (U8). Two participants used their hearing and sense of touch as a method for identifying the medicine packages; they shook them and turned them in their hands (U3, U7). One of them also had a spouse who helped her, and she always kept the medicines in a certain order to make the identification easier (U3), as described in the following comment:

...Because I have everything here in the right order. So that I know to proceed package by package, and I remember them all. (female, 84)

One participant did not fill the medicine dispenser by himself, but his spouse took care of it instead (U5). He had become blind suddenly only a year ago, and it seemed that he had not yet found ways to cope independently with the new situation.

It was common for all users who had help available that they counted on that. All users who lived with their spouses stated that they do not need the service at all, because they have help available when they need it (U1, U3, U5). One user who became blind only a year ago was positive during the initial interview and planned to try to fill the medicine dispenser himself with the help of the service. However, the result was that he had not really done that, and he still relied entirely on his spouse's help (U5). The following comments describe situations where the importance of a spouse was emphasized:

We are in a fortunate situation, because we both kind of make sure that the other has taken their medications. (male, 87)

And this is so when the mate is here who... but if you are all alone...It could be more useful in the case unless a spouse or one of the relatives is not home. (female, 84)

Some of the users commented that they would prefer a mobile solution to the stationary terminal used in the trial. With a mobile device with NFC they could touch the medicine package with the device instead of taking the medicines to the NFC-reader. However, as the users stored their medication in a fixed location, benefits were also seen in a stationary solution that would always be placed near the medication storage. The participants placed the equipment in various locations in their homes; most of them placed the computer on their kitchen table, while some of them placed it in their living room or bedroom, depending on where they took their medicines or where they had their own computer.

One user seemed disappointed with the limited and simple functionality demonstrated in the field trial. Users proposed more versatile functionalities as ideas for improvement, e.g., a reminder (U2, U1) and a control for preventing overdose (U4), as shown in the following comments: 
It is a bit hard to say (whether it has been useful)... Why not, if there were to be more functionalities in it, it could be nice. (male, 74)

It is missing a possibility to... (control medication taking) It should stop at some point. As an example, now I can take this medicine as many times as I want and it always gives me a permission to take it. (female, 73)

It must be noted that the technical setup used in the trial might have led the users to think about cost factors and the other practical difficulties of buying a laptop computer to adopt the service. Our original goal was to use mobile phones, but due to the non-availability of NFC phones, we decided to first test the concept with a laptop computer. This of course has an effect on the user experience. Users' thoughts about the computer are described in the following discussion:

Researcher: So is it nice that it (the service) is being taken away (after the pilot) or could it stay as well?

I don't know about that. That (the reader) itself (is ok) but the computer. (female, 73)

Researcher: So it (the computer) bothers you because it takes space?

Yes, Exactly. It takes one seat from the dining table. (female, 73)

\section{Barriers to technology adoption in pilot study}

In this chapter, we analyze the factors that had an influence on the perceived usefulness, i.e. benefits, of the service, and what were the barriers to adoption identified during the study.

Barrier 1. Participants in the user pilot might not consider themselves to be included in the potential user group of the service for different reasons. In this case, the users did not consider themselves to be visually impaired "enough".

Barrier 2. Participants might not have perceived actual problems in medication management for themselves and thus, they do not find the solution useful. In this case, people relied rather on their memory or on other people than on technology.

Barrier 3. Participants in the user pilot have established their own methods for medication management and thus, the solution should offer added value in order to be useful.

Barrier 4. The influence of the social environment should not be underestimated during the pilot. In this case participants preferred the help of other people to that of technology.

Barrier 5. The attractiveness and convenience of the experimental setup has an influence on how useful the people perceive the technology. In this case, some people did not find the experimental setup used in the study especially convenient.

Barrier 6. The users might have fears of showing their vulnerability. For example, the users recruited through the sheltered home might have fears that the nurses might deny them independent medication management, if they notice problems in medication management.

\section{Discussion}

Many barriers to adopting technology-supported medication management were identified. The users had developed their medication management practices for decades to fit their personal needs and requirements, and they were reluctant to change them, and actually did not think they had any need to change. The challenge was not their attitudes towards technology, but their desire not to change their identity or to make any changes to their existing practices, even though this sometimes meant a loss of independence through relying on the support of other people.

Even when the users found the service easy to adopt and use, and generally had really positive attitudes toward the system, most did not want to adopt it for permanent use.

During the study we were able to observe really closely the medication management process of the older people participating in the trial. We found that, besides their remaining sense of sight, the users mainly trusted their memory for the dosages and other methods of identification of the medicine package, such as their sense of touch and the help of other people. The variety of methods is not surprising. For example, Palen and Aaløkke have reported that people manage their medications with only partial information about what the medication is [13]. They have their own personalized arrangements and routines that they use in their homes, which assist them in medication management, even when they know very little about the medication itself. Also Beckman Gyllenstrand [3] reported that, when older people were asked about their strategies when experiencing difficulties with their medications, they answered that they find ways to manage these difficulties with or without help or aids of any kind.

We also found that users had recognised some difficulties with their medication taking, but they had learned to cope with them, and they still considered that they were managing their medicines quite well. However, Beckman Gyllenstrand [3] has found in her studies that older people's self-reported ability to manage medications correlates poorly with their actual ability. Medication management is a delicate issue, and the users might feel pressure to show competence in it, because they know that if their potential problems were revealed, their right of independent medication management could be questioned.

It has been discovered that self-identity affects acceptance of the device [11]. This could partly explain the low desire to use the service. If a person thinks he should be able to manage medication without technology, he does not want to use it because it does not fit with the technology-independent image he has of himself.

Hirsch et al. have stated that people may find that assistive devices highlight their disabilities, and they do not want to use them [8]. This might provide one explanatory factor for the fact that even participants with obvious vision impairments seemed to have a desire to show visual competence. In this case, the 
technology designed for compensating lost capability may become a reminder of the loss.

Technological support for medicine identification and audio support for internalising personalized medication information did not seem to provide additional value for our user group. The study opens up new research issues considering, for example, how older people could be better motivated to use technology that would, for example, improve their safety (regarding medicines) and provide support and help in their every day life. As an example, persuasive techniques, such as self-monitoring, could be used in order to support the selfawareness needed for recognizing the need for the service or technology. With better awareness of the problem, the users could be more motivated to change their behaviour.

\section{CONCLUSIONS}

The concept of a contactless service for supporting identification of medicine packages and retrieving medicine information was designed together with the stakeholders needed for implementing the full service chain. The service was evaluated successfully in the field trial with eight older users, and the feedback from the users was positive, although they were not willing to adopt the service for their use at the moment. The factors influencing user acceptance of a technology with older users in detail were explored, as well as the usability of a touch-to-speech user interface.

The study has some limitations. The trial period of four to six weeks might have been too short for studying the medicine management behaviour of those users who were using medicine dispensers. The everyday use situations were not as authentic as they could have been, because normally users have a need to identify their medicines and retrieve medicine information only when they are filling their medicine dispensers.

It is typical that technology pilots and field trials evaluating new innovations focus mostly on user's personal competence and technology. In this study, it was discovered that other factors, such as help available at home, may be a reason for not adopting technology. Thus, in further studies it is important to recognise the role and importance of the social environment in technology adoption.

\section{ACKNOWLEDGMENTS}

We would like to thank TopTunniste, Caritas-Säätiö (foundation in Oulu) and Finnish Federation of the Visually Impaired for their contribution. Also, we want to acknowledge the valuable contribution of the ageing users who took part in the field trials.

\section{REFERENCES}

[1] "Aging report", Economic and budgetary projections for the EU-27 Member States (2008-2060) - Statistical Annex, 2009.

[2] H. Ailisto, L. Pohjanheimo, P. Välkkynen, E. Strömmer, T. Tuomisto and I. Korhonen, "Bridging the Physical and Virtual Worlds by Local Connectivity-Based Physical Selection", Personal Ubiquitous Computing, 10, pp. $333-339,2006$.
[3] A. Beckman Gyllenstrand, "Medication management and patient compliance in old age", Thesis for doctoral degree (Ph.D.), Karolinska Institutet, Stockholm, Sweden, 2007.

[4] A. Beckman, M. G. Parker and M. Thorslund, "Can elderly people take their medicine?", Patient Education and Counseling vol. 59, no. 2, pp. $186-191,2005$.

[5] E. Faber, and H. de Vos (Eds.), "Creating Successful ICT-Services: Practical Guidelines Based on the STOF Method", Telematica Instituut, Enschede, The Netherlands, 2008.

[6] M.S. Giron, H.X. Wang, C. Bernsten, M. Thorslund, B. Winblad, and J. Fastbom, "The appropriateness of drug use in an older nondemented and demented population", Journal of the American Geriatrics Society, vol. 49, no. 3, pp. $277-283,2001$.

[7] P. von Heideken Wågert, J. Gustavsson, L. Lundin-Olsson, K. Kallin, B. Nygren, B. Lundman, A. Norberg, and Y. Gustafson, "Health status in the oldest old. Age and sex differences in the Umeå 85+ study", Aging clinical and experimental research, vol. 18, no. 2, pp.116-126, 2006.

[8] T. Hirsch, J. Forlizzi, E. Hyder, J. Goetz, C. Kurtz, and J. Stroback, "The ELDer project: social, emotional, and environmental factors in the design of eldercare technologies", in Proc. of the 2000 conference of Universal Usability (CUU '00). ACM, New York, NY, USA, pp. 72 79, 2000.

[9] J. Häikiö, A. Wallin, and M. Isomursu, "Digitally-enhanced services for the elderly", International Journal of Services Sciences, vol. 3, no. 2/3, pp. $232-249,2010$.

[10] M. Isomursu, M. Ervasti, and V. Törmänen, "Medication Management Support for Vision Impaired Elderly - Scenarios and Technological Possibilities", in Isabel 2009, 2nd International Symposium on Applied Sciences in Biomedical and Communication Technologies, 2009.

[11] Y. Lee, J. Lee, Z. Lee, "Social Influence on Technology Acceptance Behavior: Self-Identity Theory Perspective", The Database for advances in Information Systems, ACM, New York, USA, vol. 37, nos. 2 - 3, Spring-Summer 2006.

[12] L. Lines, and K.S. Hone, "Older adults' evaluations of speech output”, in Proc. of the fifth international ACM conference on Assistive technologies (Assets '02), ACM, New York, USA, pp. 170 - 177, 2002.

[13] L. Palen, and S. Aaløkke, "Of pill boxes and piano benches: "Homemade" methods for managing medication", in Proc. of the Computer Supported Cooperative Work (CSCW), ACM Press, pp. 79 - 88, 2006.

[14] M. Patton, "Qualitative research \& evaluation methods", 3rd ed., Sage publications, Thousand Oaks, London, New Delhi, 2002.

[15] E. Paul. "Reengineering Medication Management From the Bedside Using Bar-Coding and Wireless Technology", In Proc. of the Annual Healthcare Information and Management Systems Society (HIMSS) conference and Exhibition, 2000.

[16] "Prevention of Blindness and Deafness. Consultation on development of standards for characterization of vision loss and visual functioning", Geneva, 4-5 September 2003. Geneva: WHO; 2003 (WHO/PBL/03.91) [Online] Available: http://whqlibdoc.who.int/hq/2003/WHO_PBL_03.91.pdf (last accessed on 13.1.2011)

[17] B. Reeves, and C. Nass, "The media equation: how people treat computers, television, and new media like real people and places". Cambridge, UK: Cambridge University Press. Cambridge, UK, 1996.

[18] E. Rukzio, K. Leichtenstern, V. Callaghan, P. Holleis, A. Shmidt, J. Chin, "An experimental comparison of physical mobile interaction techniques: Touching, pointing, and scanning", in Proc. of the 8th International Conference on Ubiquitous Computing, pp. 87 - 104, 2006.

[19] F. Wu, F. Kuo, and L.-W. Liu, "The Application of RFID on Drug Safety of Inpatient Nursing Healthcare", in Proc. of the 7th international conference on Electronic commerce (ICEC '05), ACM Press, pp. 85 92,2005 . 